\title{
Laboreal
}

Volume $3 \mathrm{~N}^{\circ} 1$ | 2007

Varia

\section{Instrumentos conceptuais e metodológicos na análise de riscos e nos processos de prevenção : a abordagem de Véronique De Keyser}

Instrumentos conceptuales y metodológicos en el análisis de riesgos y en los procesos de prevención : el abordaje de Véronique De Keyser Instruments conceptuels et méthodologiques dans l'analyse de risques et dans les processus de prévention : l'approche de Véronique De Keyser Conceptual and methodological instruments in risk analysis and in the processes of prevention: the approach of Véronique De Keyser

\section{Camilo Valverde}

\section{OpenEdition}

Journals

\section{Edição electrónica}

URL: http://journals.openedition.org/laboreal/12822

DOI: $10.4000 /$ laboreal. 12822

ISSN: 1646-5237

\section{Editora}

Universidade do Porto

\section{Refêrencia eletrónica}

Camilo Valverde, «Instrumentos conceptuais e metodológicos na análise de riscos e nos processos de prevenção : a abordagem de Véronique De Keyser », Laboreal [Online], Volume $3 N^{0} 1$ | 2007, posto online no dia 01 julho 2007, consultado o 10 outubro 2019. URL : http://journals.openedition.org/ laboreal/12822 ; DOI : 10.4000/laboreal.12822

Este documento foi criado de forma automática no dia 10 outubro 2019.

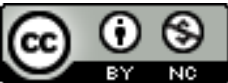

Laboreal está licenciado com uma Licença Creative Commons - Atribuição-NãoComercial 4.0 Internacional. 


\section{Instrumentos conceptuais e metodológicos na análise de riscos e nos processos de prevenção: a abordagem de Véronique De Keyser}

Instrumentos conceptuales y metodológicos en el análisis de riesgos y en los procesos de prevención : el abordaje de Véronique De Keyser

Instruments conceptuels et méthodologiques dans l'analyse de risques et dans

les processus de prévention : l'approche de Véronique De Keyser

Conceptual and methodological instruments in risk analysis and in the processes of prevention : the approach of Véronique De Keyser

\section{Camilo Valverde}

\section{NOTA DO EDITOR}

Manuscrito recebido em : Março/2007

Aceite após peritagem em : Julho/2007

\section{Biografia da autora}

Véronique De Keyser nasceu em 23 de Março de 1945 em Bruxelas.

2 Fez os seus estudos em psicologia do trabalho na Université Libre de Bruxelles. A partir de 1984 passou a estar ligada à Université de Liège, na qual dirige o Département de Psychologie du Travail et des Entreprises da Faculté de Psychologie et Sciences de L'Éducation. Ao nível de investigação tem-se dedicado às temáticas da segurança e da fiabilidade humana em sistemas de risco como a indústria nuclear, a aeronáutica e a anestesia. Especializou-se na modelação cognitiva baseada na inteligência artificial, 
concretamente no raciocínio temporal e no processo de decisão em situações dinâmicas.

3 Tem contribuído de forma relevante para a evolução da psicologia do trabalho na Europa. A sua abordagem insere-se na tradição da psicologia do trabalho francófona, que tem consolidado importantes contributos nesta área de intervenção. É uma perspectiva suportada por um paradigma de natureza contextual que privilegia a análise da actividade, realizada no seu meio natural e dinâmico, como instrumento fundamental da compreensão do trabalho na sua globalidade. Esta compreensão do trabalho visa permitir a emergência de possibilidades para a sua transformação e adaptação ao homem.

4 Foi presidente de várias associações científicas, nomeadamente da SELF Société d'Ergonomie de Langue Française e da EAWOP

5 European Association of Work and Organizational Psychology. Sendo membro do Parlamento Europeu desde 2001, tem actualmente assento na Comissão de Negócios Estrangeiros e é membro suplente da Comissão do Mercado Interno e Protecção do Consumidor e da Comissão dos Direitos das Mulheres e da Equidade dos Géneros.

\section{Introdução}

Em Portugal persistem debilidades organizativas e operacionais na higiene, segurança e saúde ocupacionais que constituem um importante desafio aos diversos stakeholders [ $\left.{ }^{2}\right]$ envolvidos na garantia da segurança, na promoção da saúde e do bem-estar dos trabalhadores. Estamos perante um domínio que claramente reclama a realização de profundas mudanças nas concepções e nas práticas da prevenção. Estas alterações solicitam a reconfiguração das representações dos actores no terreno, nomeadamente ao nível da compreensão e da transformação dos processos de trabalho que devem ser analisados na sua globalidade: desde as opções no momento da sua concepção, passando pela forma como está organizado, até às condições, muitas vezes degradadas, em que efectivamente se realiza.

7 Se assumirmos este desiderato, a abordagem de Véronique De Keyser que aqui se procura sintetizar, pode constituir um contributo relevante na medida em que permite alargar, aprofundar e reconfigurar conhecimentos e, eventualmente, transformar representações sobre formas de analisar riscos, de conceber e realizar a prevenção e de sustentar mudanças nas/das práticas deste domínio. Esta possibilidade é particularmente pertinente se tivermos em conta a contínua emergência de novos problemas de segurança e saúde ocupacionais, o surgimento de novos factores de risco nas organizações e a consequente necessidade de transformação das actuais tendências nas formas de conceber e de realizar a prevenção, até aqui muito ancoradas na estrita observância de prescrições de natureza técnica, do cumprimento de normas e procedimentos legais [3].

Para ajudar a clarificar a perspectiva metodológica de Véronique De Keyser sugerimos uma reflexão organizada em torno das três seguintes questões :

1. Como têm evoluído as formas de colocar o problema da prevenção e da avaliação dos riscos laborais?

2. Num paradigma $\left.{ }^{4}\right]$ de estudo do trabalho que se reivindica de contextual, como se pode caracterizar o contexto, como analisá-lo e como intervir nele? 
3. Em que medida a acção dos investigadores/interventores e os métodos que utilizam na avaliação de factores de risco, se transformam em verdadeiros instrumentos ao serviço da prevenção?

9 A primeira questão pode ser enquadrada num posicionamento reflexivo mais vasto sobre as formas como as diferentes disciplinas, neste caso a psicologia do trabalho, concebem e realizam a investigação e as intervenções. É um posicionamento que salienta a importância das questões metodológicas não se circunscreverem e reduzirem a processos de análise e a escolhas de natureza eminentemente técnica. É importante tomar em linha de conta que as decisões sobre os métodos são habitualmente tributárias de outras opções mais abrangentes, nomeadamente no plano epistemológico, ou seja, as opções sobre os métodos dependem essencialmente da forma como colocamos o problema, dos paradigmas que lhe estão subjacentes. Neste enquadramento, concretizaremos no ponto 1 a proposta de Véronique De Keyser sobre as evoluções e tendências nos métodos de investigação/intervenção neste domínio, analisando os diferentes paradigmas, as formas alternativas de colocar as questões, os conceitos que vão sendo mobilizados pela psicologia do trabalho para compreender os riscos e perspectivar a prevenção. A questão que se coloca, e procurará ser respondida nos pontos seguintes, é a de saber se a investigação sobre riscos no trabalho tem efectivamente influenciado a prevenção e como se podem perspectivar essas relações.

Esta proposta de análise da evolução das visões alternativas sobre a problemática dos riscos e da prevenção é apresentada como indissociável das concepções sobre o papel do "factor humano". As investigações realizadas no seio desta orientação científica têm demonstrado (Faverge, 1970) que as pessoas são vistas simultaneamente como factores de fragilidade e de garantia de eficácia e da fiabilidade dos sistemas. Isto é, face aos constrangimentos que têm de enfrentar, os humanos apresentam debilidades e podem cometer erros, mas nas situações críticas e de maiores dificuldades, os mesmos humanos revelam grande eficácia, garantindo a regulação e o controlo de sistemas cada vez mais complexos. Desta forma, o contributo das pessoas para a fiabilidade dos sistemas não pode ser perspectivado em abstracto : depende da sua formação e da sua experiência, dos recursos a que podem aceder, das condições de trabalho e da forma como está organizado. Não faz sentido, portanto, continuar a perspectivar a investigação e a acção no domínio da segurança e saúde no trabalho recorrendo à tradicional e generalizada imputação de responsabilidades individuais sobre as vítimas, concebidas abstractamente como o elo fraco que, em consequência, deve ser afastado dos níveis de regulação. Dito por outras palavras, a eficiência e eficácia das pessoas na pilotagem e regulação dos sistemas produtivos é entendida como devendo ser perspectivada a partir da análise do contexto específico em que o trabalho se realiza.

11 Assumindo esta incontornável necessidade de contextualizar as investigações e as intervenções no domínio da prevenção e da análise de riscos profissionais [5], passamos à segunda questão que desenvolvemos no ponto 2. Esta questão coloca-nos perante a pertinência de promover a operacionalidade do conceito de "contexto", analisando as diferentes teorias habitualmente utilizadas para o caracterizar, bem como os dispositivos metodológicos destinados a conceber e executar estudos e intervenções alicerçadas no terreno.

12 O contexto laboral não se esgota no meio físico em que o trabalho se realiza. Existem outras facetas do contexto que influenciam e são equacionadas na finalização da produção dos trabalhadores, na sua segurança, saúde e bem-estar. É, por isso, 
importante analisar globalmente os processos de trabalho. Em síntese, no quadro deste paradigma de natureza contextual, a abordagem proposta fornece alternativas que nos permitem enfrentar as seguintes questões :

- Que teorias alternativas são utilizadas/veis para compreender o contexto ?

- Como se pode estudar/compreender e transformar um contexto ?

- Como se distingue uma investigação/intervenção de tipo contextual de uma que o não seja ?

Por fim, a terceira questão configura-se como uma importante dimensão da perspectiva de Véronique De Keyser e será desenvolvida no ponto 3. Consiste em assumir como instrumentos [ $\left.{ }^{6}\right]$, quer a acção dos investigadores/interventores, quer a abordagem metodológica que utilizam no estudo dos riscos profissionais. Tomando como referência a teoria de Vygotski, muito influente na psicologia do trabalho francófona, podemos considerar os métodos e o papel dos investigadores/interventores como ferramentas. Para que estas ferramentas deixem de ser meros artefactos e se configurem como verdadeiros instrumentos, é necessário que as pessoas, ao utilizá-las, se apropriem delas, transformem as suas práticas, alterem as suas representações e possam aceder a uma mundividência diferente (De Keyser \& Nyssen, 2001). Assim, podemos dizer que é nossa intenção descrever os artefactos da análise e avaliação de riscos e verificar de que forma se tornam verdadeiros instrumentos ao serviço da transformação das concepções e das práticas da prevenção.

\section{Evolução dos paradigmas na análise dos riscos}

14 Sendo o estudo de riscos uma actividade determinante para a gestão da segurança e saúde no trabalho, comecemos por caracterizar as evoluções dos paradigmas, das ideias que têm sido mais influentes neste domínio, de forma a compreender as implicações que daí podem decorrer para a prevenção, nomeadamente para possibilitar a emergência de formas alternativas de a perspectivar e concretizar.

$\mathrm{Na}$ análise destas evoluções podemos facilmente constatar que existem muitos riscos que têm adquirido diferentes configurações e impactos em diversos locais e momentos históricos. Actualmente falamos muito dos riscos psicossociais, mas o esforço pela segurança no trabalho foi historicamente o primeiro grande desafio colocado à psicologia do trabalho, à medicina do trabalho, aos serviços de segurança, aos sindicatos e a uma série de outros actores e instituições que se colocaram no terreno para tentar controlar os acidentes de trabalho. Podemos dizer que globalmente se conseguiram bons resultados na Europa ocidental porque os indicadores de mortalidade e de morbilidade associáveis ao trabalho evoluíram positivamente.

Coincidente com as evoluções tecnológicas e com as alterações do mercado em geral começou a falar-se em erro humano. Não quer isto dizer que tenha deixado de haver acidentes de trabalho: o que se verifica é que ao nível da investigação começa a emergir gradualmente a problemática do erro humano. Na verdade, na análise dos grandes acidentes (Chernobyl, Three Mile Island...), tem-se levantado a questão de que apesar da limitação geral dos riscos, persiste o risco do erro humano que pode conduzir a catástrofes. Assim, a partir dos anos 80 verifica-se um considerável aumento de publicações sobre o erro humano.

17 Sem que o erro humano tenha diminuído de importância, verifica-se, contudo, o aparecimento de outros fenómenos. Profusamente difundidos, o stresse e os riscos 
psicossociais passam a estar na ordem do dia e o assédio moral passa a constituir um tema emergente da prevenção na Europa ocidental. Com este breve esboço da evolução dos temas dominantes podemos concluir que os riscos gerados pelas condições de trabalho não cessam de se desenvolver a nível mundial e que estão sempre presentes, embora com variações de intensidade em função da época e dos países em que ocorrem.

Antes de iniciarmos a caracterização dos diferentes paradigmas utilizados, evidenciamos uma importante ideia sugerida por Véronique De Keyser (2001a) que consiste em verificar que a psicologia do trabalho tem oscilado entre as tendências em privilegiar como unidade de análise no estudo dos riscos o indivíduo ou o sistema. Efectivamente, para cada um destes temas (acidentes de trabalho, erro humano, stresse, assédio moral, etc.) tem sido clara a alternância de abordagens de tipo individual e de abordagens focalizadas no sistema. Para bem compreender estas oscilações, a autora considera que :

Para além da dicotomia de abordagens, estamos perante duas ideologias. Focalizar a investigação no indivíduo, particularmente na área dos acidentes de trabalho, suprime a influência do ambiente de trabalho no aparecimento do fenómeno. Procuram-se as causas e as respostas ao problema nas pessoas. Na perspectiva oposta, focalizar no sistema concede um estatuto idêntico ao homem e à máquina, deixando na penumbra as diferenças interpessoais, o livre arbítrio e as emoções que constituem partes importantes do trabalho (idem, p. 3-4, tradução livre).

19 Na tentativa de ultrapassar esta dicotomia sustenta que a prevenção deve configurar-se elegendo "o ser humano considerado em contexto como agente de fiabilidade que ajuda a controlar o sistema, se for devidamente apoiado tecnologicamente na sua actividade" (idem, p. 4, tradução livre). Esta terceira via para a prevenção constitui uma das ideias mais importantes na abordagem perspectivada por Véronique De Keyser, facto que procuraremos ilustrar ao longo deste trabalho.

\subsection{A abordagem individual}

Como já referimos, a segurança constituiu a primeira preocupação da prevenção na Europa. $\mathrm{Na}$ opinião da autora, a intervenção no domínio dos acidentes foi originariamente baseada em duas tendências. Uma orientada para técnicas destinadas a restringir o perigo das máquinas e dos diversos riscos do meio físico de trabalho. A outra tendência era orientada para os indivíduos, a quem considerava "como vítimas responsáveis pelos seus próprios acidentes” (De Keyser, 2001a, p. 4, tradução livre). Historicamente, falamos de um período anterior à Primeira Guerra Mundial, em que se acreditava que a psicologia, socorrendo-se dos princípios da psicotécnica então nascente, poderia contribuir para a compreensão e para o controlo do factor humano, "imprevisível e complicado por definição" (idem). A questão estruturante desta abordagem era "a quem acontecem acidentes ?" (idem). A análise de riscos e a gestão da prevenção gravita em torno do indivíduo e utiliza-se a psicotécnica para seleccionar os indivíduos que possam ser considerados como factores de risco. 0 objectivo consiste em exclui-los do trabalho, sobretudo dos postos mais perigosos ou que envolvem maior responsabilidade.

21 A França foi um país pioneiro desta perspectiva, destacando-se no seu desenvolvimento figuras como Lahy, Pacaud e Bonnardel, que desenvolveram importantes trabalhos, 
particularmente no sector dos transportes. Trata-se de uma abordagem suportada por um paradigma experimental em que se comparam pessoas com vários acidentes ao longo da sua vida profissional, denominadas poli-acidentadas, com pessoas sem acidentes. Através do recurso aos métodos de avaliação, era pressuposta a existência de diferenças estatisticamente significativas nas características pessoais entre os membros dos dois grupos (De Keyser, 2001a).

Os processos de recrutamento e selecção são o principal instrumento utilizado nesta abordagem. A sua finalidade é a deteç̧ão de características pessoais passíveis de se configurarem como factores de risco para a segurança no trabalho e, consequentemente, eliminar os candidatos que revelem propensão para a sinistralidade. Contudo, a partir do final dos anos 50 os testes, instrumento privilegiado nesta concepção, foram alvo de violenta contestação, tanto no plano científico como no ideológico. De Keyser, (2001a) evidencia críticas que acusavam os testes e questionários de apenas reflectirem o ponto de vista biosociológico que explica as causas do insucesso escolar através da hereditariedade e das aptidões inatas. São igualmente salientadas as posições que denunciavam a ilusão dos adeptos da psicometria pelo facto de acreditarem que os resultados são independentes do contexto educacional se forem usados testes de inteligência não verbais e abstractos. Também é referida a posição que considerava que os testes de personalidade não eram científicos e pretendiam, acima de tudo, testar a potencial lealdade dos candidatos.

A autora considera que a prevenção de acidentes alicerçada na selecção foi afectada por este movimento crítico, particularmente no que respeita ao conceito de propensão individual para o acidente. "Tornou-se progressivamente evidente que excluir as pessoas poli-acidentadas não era suficiente para uma boa prevenção: os acidentes também acontecem aos outros, se o contexto de trabalho os originar" (De Keyser, 2001a, p. 6, tradução livre).

\subsection{Sistemas homem-máquina}

Nos anos 60 verificam-se significativas alterações no estudo dos acidentes laborais. "A questão fundadora deixa de ser a quem acontecem os acidentes? para passar a ser : em que situações a probabilidade de acidentes aumenta ?" (De Keyser, 2001a, p. 7, tradução livre). Esta forma alternativa de perspectivar os acidentes implicou a emergência de modelos de tipo probabilista em detrimento dos modelos de natureza causal, até então dominantes. Assim, em vez de salientar a determinação da causa dos acidentes, "passa a ser fundamental detectar, nos eventos que os precederam, que sequência de factores conduziram à sua ocorrência" (idem). Ou seja, a unidade de análise deixou de ser o indivíduo visto isoladamente para passar a ser o conjunto das interfaces do sistema homem-máquina perspectivado na sua globalidade.

Estamos perante um alargamento da visão dos investigadores que deixam de estar apenas focalizados no acidente em si, para se interessarem com a sucessão dos eventos que os precederam, tais como, falhas de organização, avarias e outros sintomas reveladores de disfunções do sistema no seu conjunto, que ultrapassam em muito os factores restritos habitualmente equacionados na análise dos acidentes. Esta inversão da análise da problemática dos acidentes do indivíduo para o sistema considerado na sua globalidade, é acompanhado, na opinião da autora, pela valorização do conceito de fiabilidade $\left.{ }^{7}\right]$ do sistema em detrimento do conceito de segurança (De Keyser, 2001a) 
Esta alteração decorre da progressiva visão de que os acidentes podem ser previsíveis, nomeadamente através do recurso a estatísticas que estimam a sua probabilidade de ocorrência, abrindo espaço à prevenção que procede pela eliminação ou minimização dos factores de risco. Esta forma de ver contraria a anterior visão de que os acidentes são imprevisíveis e têm origem na falta de rigor e de fiabilidade do factor humano e fica possibilitada a representação de que "o ser humano é um factor de risco entre outros, um dos elementos do sistema homemmáquina" (De Keyser, 2001a, p. 7, tradução livre).

Para compreender esta inversão na forma de colocar o problema dos acidentes, é importante invocar, de acordo com a perspectiva que aqui se caracteriza, a confluência de um conjunto de factores. Em primeiro lugar, o desalento com os resultados alcançados com a psicotécnica. Depois, a criação nos anos 60 de um grande conjunto de programas de investigação, patrocinados e coordenados no plano Europeu pela Comunidade Europeia do Carvão e do Aço com o objectivo de garantir a protecção da saúde e a segurança dos trabalhadores ligados à produção do aço e à extracção mineira. Estes estudos, conduzidos por equipas universitárias em diferentes países, numa época em que a perspectiva sistémica tinha um grande impacto na comunidade científica, foram realizados fora do laboratório, em estreita articulação com o terreno. Facilitouse, desta forma, a emergência de novas leituras, de teorias e de modelos alternativos na compreensão dos acidentes, em que se valorizava a sucessão de sintomas que se combinam para os originar em detrimentos das causas individuais.

o sistema homem-máquina é claramente tributário da perspectiva sistémica: a organização é tomada como um conjunto que persegue finalidades e que possui subsistemas interactivos que efectuam trocas de vária natureza e entre si e com a sua envolvente que podem de ser operacionalizadas. Nem todos os resultados do sistema são positivos, como por exemplo a elevada produtividade e a excelência técnica. Os sistemas também geram erros, avarias e acidentes. Estes outputs desejáveis e indesejáveis não devem ser vistos isoladamente porque podem ser originados pelos mesmos factores, como acontece no exemplo da ausência de manutenção preventiva de uma máquina que pode repercutir-se ao nível da qualidade, da produtividade, da sinistralidade (De Keyser, 2001a).

Nesta perspectiva os incidentes são particularmente importantes na prevenção porque constituem indicadores de menor segurança ou fiabilidade do sistema. Este aspecto foi particularmente salientado por Faverge (1967) que refere ser constatável estatisticamente o aumento da probabilidade de acidentes quando ocorrem incidentes resultantes de disfunções no sistema. Assim, é importante na análise dos acidentes que se observem os fenómenos no terreno, se apreenda a cadeia de eventos que os precederam, a caracterização das dimensões temporal e histórica que lhe estão associadas. Estas informações são muito mais importantes para a determinação da probabilidade de ocorrência dos acidentes e, consequentemente, para a prevenção do que a prática bastante difundida que consiste na declaração de acidentes que pode conter atribuições causais enviesadas, omissões e outras informações menos relevantes para a eliminação ou minimização dos riscos (idem).

Nesta abordagem do sistema homem-máquina, teórica e metodologicamente ancorada em investigações empíricas empreendidas no terreno, particularmente a escola francófona, fortemente influenciada pela teoria da actividade, confere um grande protagonismo ao operador como actor fundamental na regulação do sistema. Em vez de ser apenas considerado como um factor de risco, desempenha um papel que as 
máquinas não podem garantir : detecta, antecipa e controla incidentes, prevenindo muitos acidentes e catástrofes (De Keyser, 2001a ; Faverge, 1970). “Contudo, nos anos 60, a escola francófona impediu a expressão da emoção. Interessou-se pelo comportamento humano, pelos conhecimentos dos sujeitos, mas permaneceu desinteressada do seu discurso, do seu stresse e do seu sofrimento no trabalho" (De Keyser, 2001a, p. 8, tradução livre).

\subsection{Erro humano}

De Keyser considera que o erro humano é uma invenção dos meios de comunicação social nos anos 80 (De Keyser, 2001a). Sobretudo a propósito das grandes catástrofes, a comunicação social salienta habitualmente as consequências dos erros humanos, enfatizando a associação entre o erro e o desastre e omitindo, muitas vezes, outras dimensões como o contexto, a tecnologia, a actividade e a história dos actores envolvidos. Ao conceito de erro humano a comunidade científica procurou contrapor "processo incidental, fiabilidade humana, acto erróneo" (De Keyser, 2001a, p.12, tradução livre), contudo, apesar da consideração pelos cientistas do seu carácter ambíguo e pouco operacional, o conceito acabou por se impor a toda a sociedade. A autora considera que esta imposição da noção de erro humano "parece ser um retrocesso face ao padrão sistémico que favoreceu o sistema homem-máquina como unidade de análise e a abordagem à fiabilidade humana a partir de uma enquadramento probabilístico". (idem, p. 9, tradução livre).

31 Em detrimento da visão de que é normal os humanos errarem e que os erros devem ser tolerados e utilizados como fonte de aprendizagem, privilegiando-se que os sistemas sejam concebidos de forma a permitir a sua atempada detecção e a adopção de estratégias que os recuperem, emergiu o ponto de vista de que os humanos são falíveis por natureza e constituem o maior risco na cadeia de funcionamento do sistema. Em congruência com esta visão, o recurso à informatização e automatização configura-se como uma adequada estratégia para os afastar da produção ou para reduzir o seu protagonismo na regulação dos sistemas.

32 As ambiguidades associadas ao conceito de erro humano começam com a sua própria definição. O erro é considerado por muitos autores de referência neste domínio (Norman 1981, Reason 1990, Hollnagel 1994, cit. in De Keyser, 2001a ; Leplat, 1995) como "discrepância em relação a um referencial reconhecido como correcto (norma, modelo, teoria, conhecimento estabelecido) apesar de o sujeito tentar estar de acordo com esse referencial" (De Keyser, 2001a, p. 9, tradução livre). É salientada ainda "a necessidade de o sujeito possuir margem de liberdade para pensar ou agir de acordo com o referencial" (Reason, 1990, cit. in De Keyser, 2001a, p.9, tradução livre). Na operacionalização deste conceito é importante considerar ainda que :

Os erros humanos não devem ser concebidos como devidos à simples incompetência dos operadores, apesar de em muitos casos constituírem o resultado das suas melhores tentativas para cumprir os objectivos ;

- Os erros humanos são eventos multifacetados ;

- Os erros humanos deveriam ser considerados como incompatibilidades homem-máquina, em que os dois componentes do conjunto do sistema homem-máquina entram num estado de conflito de parceria no sistema. 0 que é determinante é circunscrever o que funcionou mal 
(i.e. o potencial conflito entre os dois parceiros no sistema) e não avaliar quem tem de ser culpabilizado pelo erro (Bagnara et al., 1990, cit. in De Keyser, 2001a, p. 9, tradução livre).

Rasmussen e Reason, que inicialmente tinham uma orientação sobretudo cognitiva das suas investigações, têm-se vindo a revelar mais sensíveis aos aspectos organizacionais e ergonómicos. A consciência de que a crescente complexidade dos sistemas técnicos, que nem sempre equaciona os limites cognitivos humanos, tem contribuído para que as investigações aplicadas se pautem por não separar os aspectos cognitivos dos aspectos organizacionais na compreensão e intervenção no domínio dos erros humanos. Isto é, na gestão dos riscos, o erro humano aparece como um dos aspectos a equacionar no conjunto do funcionamento do sistema organizacional e que, muitas vezes, a sua origem e a forma como se configura está relacionada com as dificuldades dos indivíduos confrontados com a regulação de sistemas cujo controlo é cada vez mais complexo.

\subsection{Bem-estar no trabalho}

Apesar dos problemas da segurança e do erro humano continuarem a manter a sua actualidade e pertinência, a partir de meados dos anos 70 , com a crise do petróleo, verificou-se a emergência de riscos sociais associados ao desemprego e à exclusão social. A flexibilidade exigida às empresas, a crescente tensão e pressão do trabalho, a instabilidade dos empregos, a globalização da economia de mercado que a todos afecta, constituem factores geradores de riscos directos e indirectos nos cidadãos de todo o mundo.

O quadro económico e social que emergiu é marcado pelo aumento da competitividade a todos os níveis. Verificam-se no mundo empresarial uma profusão de processos de falências, de deslocalizações, de fusões e de reestruturações. O desemprego deixou de 
ser conjuntural, oscilando de acordo com os ciclos da economia, e passou a ser estrutural, podendo manter-se elevado, mesmo quando são evidentes as recuperações e crescimentos económicos. Trata-se de um clima social passível de ameaçar a coesão e originar fracturas e exclusões, afectando a sociedade em geral, as empresas e os indivíduos.

Embora possa não traduzir o quadro sócio-económico na sua globalidade, este contexto tem favorecido o surgimento dos denominados riscos psicossociais, de que se destacam o stresse, o burnout, o assédio moral e a agressividade psicológica. Estes riscos têm vindo a ganhar centralidade na comunidade científica, nos governantes, nos legisladores, nos sindicatos, nos empregadores, na opinião pública em geral, primeiro nos países da Europa do Norte e progressivamente de forma mais generalizada.

O stresse no trabalho tem sido o tema que mais tem concentrado as atenções. Pode definir-se como "a resposta do trabalhador confrontado com as exigências de uma situação para a qual duvida ter os recursos necessários e em relação à qual estima dever fazer face" (De Keyser \& Hansez, 1996 ; De Keyser, 2001a, p. 21, tradução livre). É um problema com grande impacto no funcionamento das empresas e que afecta o quotidiano dos trabalhadores, particularmente nos contextos em que mais se faz sentir a violência, de que são exemplo as profissões que envolvem relação com o público nas quais as agressões são frequentes : nas escolas, nos transportes públicos, na segurança pública, no comércio, etc. Na sua origem estão algumas características que os trabalhadores cada vez mais frequentemente vivenciam no desempenho das suas funções nos sistemas produtivos actuais :

42 Frustrações repetidas, objectivos conflituantes, ambiguidades de papel, tensões nas relações laborais, fortes pressões temporais e, por vezes, condições de trabalho que permanecem desagradáveis (...) o receio de perder o emprego, de não ser capaz de fazer face às contínuas exigências sob ameaça de ser marginalizado e excluído (De Keyser, 2001a, p. 21, tradução livre).

Apesar da literatura sobre avaliação da fiabilidade humana, nomeadamente através do método CREAM (Cognitive Reliability and Erros Analysis Method) proposto por Hollnagel (1998, cit. in De Keyser, 2001a, p. 16), mostrar a importância dos factores que influenciam, moldam o desempenho, salientando a necessidade dos operadores possuírem autonomia para monitorizar o ajustamento desses factores, constata-se que as investigações e intervenções sobre o stresse têm sobretudo favorecido a acção sobre o aumento de defesas dos indivíduos para lidarem com as situações de trabalho stressantes, em desfavor das acções ao nível organizacional que erradiquem os factores que potencialmente o originam. Efectivamente, em detrimento da prevenção primária, privilegia-se por norma o recurso a programas dirigidos ao aconselhamento individual e a mudanças no estilo de vida pessoal.

Na sequência desta dicotomia entre a valorização da acção sobre o sistema ou sobre os sujeitos, quando se pretende promover a fiabilidade dos sistemas, questão que constitui uma dimensão fundamental na abordagem de Véronique De Keyser, como referimos várias vezes neste texto, pode ficar melhor esclarecida com a seguinte interrogação da autora, enfatizando que a eficiência da prevenção deve ancorar-se na sua adequação às especificidades do contexto em que a actividade ocorre :

45 Estamos perante a mesma conclusão a que chegou Faverge (1967) quando falou na fiabilidade do sistema? Que acidentes, incidentes, erros - acrescentemos stresse, burnout e assédio moral - se devem todos aos mesmos factores, ou seja, a uma mesma 
patologia geral do sistema de produção, e que tratar uns é equivalente a tratar os outros ? Seria ir longe demais. É antes a análise de uma actividade concreta e a recolha de dados empíricos que conduz à definição da prevenção adequada (De Keyser, 2001a, p. 22, tradução livre).

Em jeito de conclusão neste primeiro ponto sobre a evolução dos paradigmas da análise de riscos preconizada pela abordagem que vimos descrevendo, constata-se que desde o início do século XX se verificaram significativas melhorias nos processos e nas condições trabalho. São visíveis melhorias dos indicadores de segurança e saúde ocupacionais, com decréscimo da incidência e da gravidade dos acidentes e pelo esforço em evitar as doenças profissionais. Contudo, os riscos não cessam de se manifestar e de sofrer alterações. Actualmente, apresentam particular relevância nos países ricos do hemisfério norte as pressões que resultam da grande competição da economia globalizada e as dificuldades de regulação decorrentes da complexidade crescente dos sistemas técnicos.

Apesar dos diferentes paradigmas apresentados preconizarem visões alternativas sobre a análise de riscos e a gestão da prevenção nos meios laborais, verifica-se uma grande persistência na acção sobre o pólo do factor humano em detrimento da acção sobre o pólo do contexto e sobre as interfaces entre os dois pólos. Perante os diversos tipos de risco (acidentes, erro humano e psicossociais : stresse, burn out e assédio moral) tem sido dominante a tendência para agir sobre o factor humano, excluindo-o dos níveis de regulação, culpabilizando-o pelos erros, afastando-o dos postos mais exigentes, seleccionando os mais adaptados, curando os mais frágeis, etc. Compreende-se bem a afirmação: "tem havido uma obstinação dos investigadores em permitirem a emergência do contexto e em gerirem a prevenção atacando o problema da interacção entre o homem e o seu meio" (De Keyser, 2001a, p. 23, tradução livre).

\section{Abordagem contextual}

Temos vindo a salientar desde o início que a abordagem metodológica aqui proposta sustenta que a avaliação de riscos e a gestão da prevenção em segurança e saúde no trabalho deve estar alicerçada num paradigma contextual. As investigações sobre os riscos profissionais têm demonstrado, como ilustramos no ponto anterior, que o contexto é determinante na compreensão da sua origem, da sua natureza e das suas consequências. Contudo, a emergência do contexto enquanto conceito incontornável nos estudos e intervenção nesta área não tem sido acompanhada por um acordo consolidado sobre a forma de o descrever e poder predizer os aspectos do meio que podem ser pertinentes para o operador. Assim, neste segundo ponto procuramos descrever os conceitos e as teorias que permitem definir o contexto e circunscrever o que se entende por uma abordagem contextual na investigação/intervenção neste domínio.

\subsection{Caracterização do contexto}

Podemos considerar o contexto como "o subconjunto do meio que é significativo para o operador" (De Keyser, Nyssen, Hansez \& Javaux, 2001, p.53, tradução livre). Para melhor se compreender este conceito comparamos três teorias contextuais : a acção situada, a teoria da actividade e a cognição distribuída, sintetizadas na figura 1. 
Figura 1 - Comparação entre três teorias contextuais

\begin{tabular}{|c|c|c|}
\hline Acção Situada & Teoria da Actividade & Cogniçāo Distribuída \\
\hline $\begin{array}{l}\text { 1. É dada ênfase ao carácter } \\
\text { emergente, contingente da } \\
\text { natureza humana e na forma } \\
\text { como a actividade procede } \\
\text { directamente das particulari- } \\
\text { dades de uma dada situa- } \\
\text { ção. } \\
\text { 2. Por conseguinte, a unida- } \\
\text { de de análise não é o indivi- } \\
\text { duo, nem o meio, mas uma } \\
\text { relação entre os dois. } \\
\text { 3. O "setting" é definido } \\
\text { como uma relação entre pes- } \\
\text { soas em aç̧ão e a arena } \\
\text { (contexto) na qual actuam. } \\
\text { 4. A "arena" è uma estrutura } \\
\text { institucional estável. }\end{array}$ & $\begin{array}{l}\text { 1. É dada ênfase à finalidade } \\
\text { de um comportamento. } \\
\text { 2. A unidade de análise ê } \\
\text { uma actividade. } \\
\text { 3. Um sujeito é uma pessoa } \\
\text { ou um grupo envolvido numa } \\
\text { actividade. } \\
\text { 4. Um objecto é aquilo que é } \\
\text { pretendido pelo sujeito, mo- } \\
\text { tivando a sua actividade, } \\
\text { dando-lhe uma direcção es- } \\
\text { pecífica (cf. motivação) (cf. } \\
\text { meta). Os objectos (no senti- } \\
\text { do de objectivos) podem } \\
\text { mudar durante o curso da } \\
\text { acção. } \\
\text { 5. Acções sāo processos } \\
\text { orientados por objectivos } \\
\text { que devem ser alcançados } \\
\text { para cumprir o objecto. } \\
\text { 6. Operaçôs são processos } \\
\text { de rotina mais inconscientes. } \\
\text { 7. A ideia chave é a mediação } \\
\text { pelos artefactos. Artefactos } \\
\text { são os instrumentos, símbo- } \\
\text { los e linguagem que me- } \\
\text { deiam a actividade e são } \\
\text { criados pelas pessoas para } \\
\text { controlarem o seu próprio } \\
\text { comportamento. } \\
8 \text {. O contexto é a própria ac- } \\
\text { tividade. }\end{array}$ & $\begin{array}{l}\text { 1. É dada ênfase à distribui- } \\
\text { ção do conhecimento entre } \\
\text { os individuos e o seu meio, o } \\
\text { mundo. } \\
\text { 2. A unidade de análise é um } \\
\text { sistema cognitivo composto } \\
\text { pelos individuos e pelos ar- } \\
\text { tefactos que usam. } \\
\text { 3. A abordagem é a aborda- } \\
\text { gem clássica da ciência cog- } \\
\text { nitiva tradicional, mas enfati- } \\
\text { za as representaçōes do } \\
\text { conhecimento simultanea- } \\
\text { mente nas "cabeças" dos in- } \\
\text { divíduos e nos artefactos. }\end{array}$ \\
\hline
\end{tabular}

(Fonte : Adaptado de Nardi, 1996, cit. in De Keyser et al., 2001, p. 52, tradução livre)

diferente por cada uma das três teorias. Contudo, todas o concebem como “(...) sempre ligado à actividade, e concebem o meio a partir de tudo o que é circundante, que pode ser estável ou variável, e que constitui, simultaneamente, uma fonte de recursos e de constrangimentos" (De Keyser, et al., 2001, p. 52, tradução livre).

51 Assumindo a definição anteriormente referida que vê o contexto como o subconjunto do meio relevante para a aç̧ão do operador, coloca-se a questão de identificar, sobretudo de forma antecipada quais as dimensões do meio que terão relevância para o agir do operador e, subsequentemente terão de ser activadas. A figura 2 configura uma resposta a esta questão ilustrando três diferentes formas de perspectivar o contexto, como a seguir. 


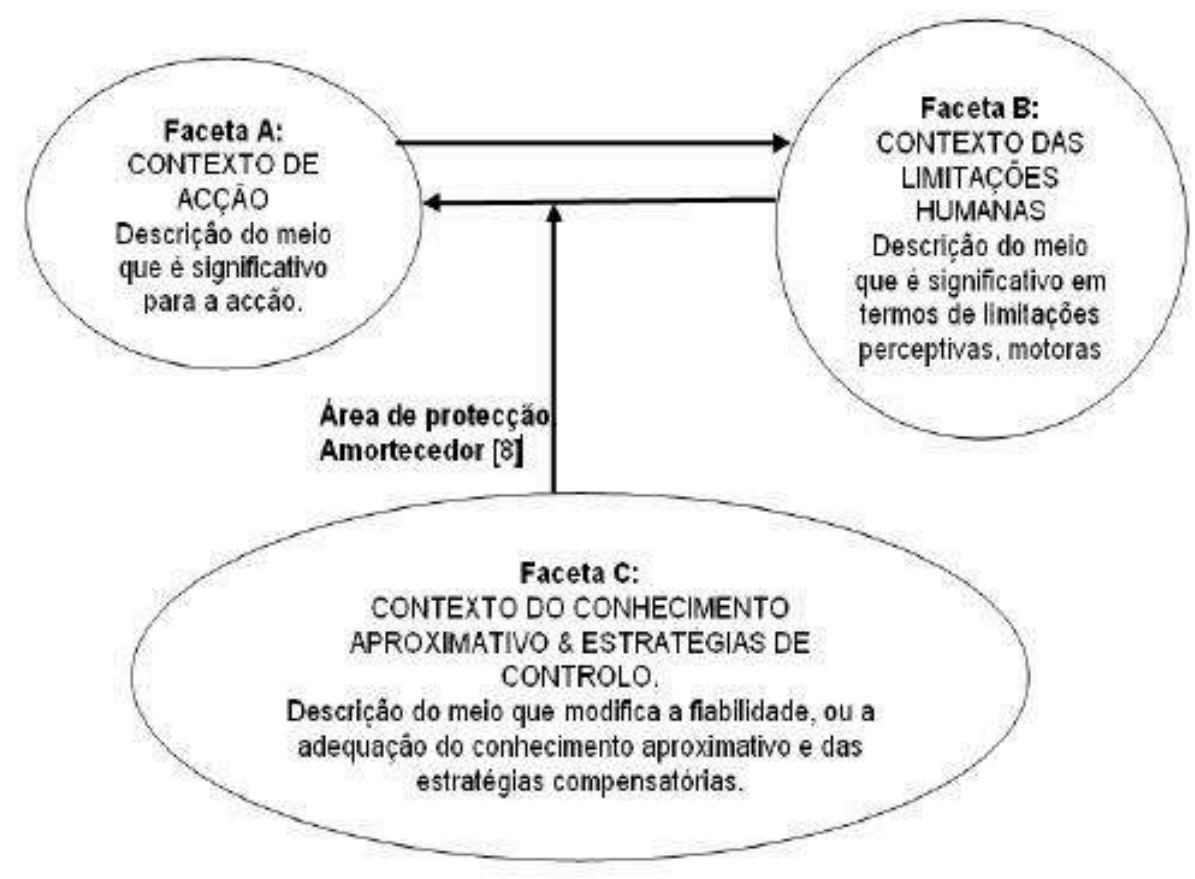

(Fonte : De Keyser \& Javaux, 1999, cit. in De Keyser et al., 2001, p. 53, tradução livre)

De acordo com De Keyser, et al. (2001) :

- A faceta A perspectiva o contexto como intimamente associado à teoria da actividade e constitui uma visão muito difundida na comunidade científica ligada à ergonomia de inspiração francófona. $\mathrm{O}$ conjunto dos objectivos, dos meios e das condições da actividade constituem o contexto. A análise da tarefa permite antever as dimensões do meio que serão relevantes para favorecer a acção do operador. Nesta perspectiva a deficiência de meios ou recursos necessários para a efectiva realização dos objectivos da actividade, origina habitualmente factores de risco para o operador e pode ser uma importante fonte de erros.

- Na faceta B, o contexto é perspectivado a partir da caracterização das características do meio que constrangem e limitam as capacidades cognitivas, perceptivas, motoras ou emocionais dos operadores, de que são exemplo as pressões temporais e climas sociais de grande tensão cognitiva ou emocional. Nesta forma de ver o contexto é muito importante o recurso a modelos teóricos consistentes sobre o funcionamento humano, como, por exemplo, os modelos de avaliação da complexidade cognitiva associados ao uso de software. Quando as capacidades ou limitações humanas são ultrapassadas, aumenta-se a possibilidade de surgirem factores de risco que podem degradar o desempenho, provocar erros e por em causa a segurança e o bem-estar dos trabalhadores.

- Na faceta $\mathrm{C}$ o contexto é visto como a descrição do meio que modifica a fiabilidade ou a adequação dos conhecimentos aproximativos e das estratégias compensatórias dos operadores. Estes frequentemente mobilizam conhecimentos e estratégias de controlo efectivas que ultrapassam os seus limites: em situações de grande complexidade, o ajustamento e a regulação é garantida por conhecimentos operativos, incompletos, aproximativos, distorcidos, mas que se revelam bastante funcionais e efectivos. Podemos dizer que os conhecimentos aproximativos e as estratégias de controlo funcionam como 
amortecedores (ver nota 8), como área de protecção como compatibilização de ritmos e de fluxos, que apesar das limitações humanas, possibilitam a adaptação dos operadores a contextos de grande complexidade. Assim, nesta perspectiva é muito importante para a fiabilidade dos sistemas evitar contextos em que os conhecimentos aproximativos deixem de ser operativos ou que as estratégias compensatórias falhem, verificando-se as designadas 'rupturas no compromisso cognitivo' (Amalberti, 1996).

\subsection{Investigação e intervenção em contexto}

desenvolver consiste em considerar que a unidade de análise das investigações/ intervenções sobre prevenção e análise de riscos laborais é o terreno, perspectivado como o conjunto dos actores individuais e colectivos que actuam num determinado domínio, caracterizado por regras e procedimentos específicos nos planos formal e simbólico. A lógica que preside a este posicionamento pressupõe que os resultados da investigação têm como destinatário privilegiado o terreno, de forma a possibilitar a sua principal finalidade : a prevenção. Para que esta se possa concretizar é necessário que os stakeholders (ver nota no 2 ) no terreno acedam a novas ideias/informações, se apropriem delas e as difundam, transformando assim as representações e os conhecimentos vigentes no seus domínios, de forma a produzir mudanças ao nível das práticas e dos valores que lhe estão subjacentes (De Keyser, et al., 2001).

como Vygotski sustenta, esta perspectiva constitui uma clara ilustração do papel dos investigadores como instrumentos ao serviço da facilitação/mediação das transformações das formas de conceber e de realizar a prevenção no terreno e é considerada no âmbito desta abordagem como sendo : imaginar que temas tão sensíveis como a prevenção pudessem ser tratados com exclusiva preponderância da comunidade científica. Metodológico porque as investigações dirigidas para o terreno para serem credíveis devem estar solidamente alicerçadas num profundo conhecimento do domínio em que ocorrem, facto que requer investimentos financeiros, tempo e esforço (idem, p. 57, tradução livre).

$\mathrm{Na}$ contextualização das intervenções aqui preconizadas é indispensável que os investigadores se integrem no terreno. É uma forma de colocar as questões da investigação e da intervenção neste domínio que faz claras exigências ao nível do seu longo tempo de duração. Antes de mais, os investigadores têm de se familiarizar com as especificidades do terreno, com a compreensão das actividades que aí se realizam e com a construção de relações de confiança com os actores em presença. Para tal têm de realizar leituras, participar em processos formativos e efectuar longas observações, que habitualmente envolvem grande permanência no terreno. Trata-se de uma abordagem que coloca o problema da investigação de forma alternativa à que se verifica na tendência bastante generalizada que se caracteriza pela prática dos investigadores recolherem informação, processarem os dados e produzirem conclusões sem se 
deslocarem, ou fazerem-no de forma deficitária, aos contextos que supostamente são o seu objecto de estudo.

Num paradigma de investigação de tipo contextual considera-se que a publicação e difusão de conhecimentos é um objectivo importante para os investigadores, mas realça-se o seu papel de agentes facilitadores de transformações consistentes e duradouras no terreno. Para se produzirem os resultados que sustentam essas mudanças é habitualmente necessário promover uma estreita cooperação interdisciplinar com os diversos actores do terreno, tanto no plano individual como no institucional. Uma vez mais o tempo é fundamental para garantir a experiência e a especialização dos investigadores, para consolidar o seu conhecimento, a sua integração e a sua aceitação no terreno. Podemos falar do desenvolvimento de relaçães e de competências que permitam esbater e transpor as barreiras disciplinares e confrontar diferentes formas de ver, diferentes saberes e conhecimentos, diferentes procedimentos e ferramentas com a finalidade de co-construirem soluções mais complexas e adaptadas às especificidades do terreno.

Assim podemos admitir como ilustrativo desta lógica contextual de perspectivar a investigação/intervenção a opinião de fendida por De Keyser, et al que consideram que :

“(...) O que faz a diferença entre investigação aplicada e investigação fundamental não são tanto as hipóteses propostas, os métodos utilizados, nem o valor intrínseco, mas muito mais a dinâmica dos efeitos e dos resultados restituídos aos actores do terreno" .(2001, p. 84, tradução livre).

\section{Os métodos como instrumentos}

Neste último ponto pretendemos descrever os métodos de prevenção de riscos e a forma como podem tornar-se instrumentos (ver nota $\mathrm{n}^{\circ} 6$ ). Se considerarmos os métodos como ferramentas, podemos distinguir nestas o artefacto do instrumento. 0 artefacto refere-se ao invólucro, à aparência do instrumento, podendo ser material ou simbólica. $\mathrm{O}$ instrumento refere-se ao uso que as pessoas lhe dão, à apropriação e adaptação do artefacto quando realizam uma tarefa, a qual pode não coincidir com o uso formal previsto pelos conceptores.

61 Para combater os riscos, para melhor os compreender e gerir, a prevenção tem vindo a alicerçar-se nas seguintes ideias dominantes, muito influenciada ao nível dos conceitos e das práticas pela teoria da actividade :

- Design e concepção adaptados ao homem ;

- Sistemas tolerantes a falhas ;

- Assistência técnica e ajudas inteligentes ao operador ;

- Complexidade dos sistemas 'governável' ;

- Generalização dos simuladores na formação ;

- Colecção e classificação de acidentes, incidentes e erros que são armazenados em bases de dados e continuamente utilizados no design, na formação e na organização do trabalho ;

- Ênfase crescente na recuperação e na gestão dos erros (De Keyser \& Nyssen, 2001, p. 25, tradução livre). importância que atribui aos conceitos de contexto e de instrumento. Apesar da sua 
origem já longínqua [8], esta teoria tem sido alvo de interesse crescente na actualidade. Muitos autores consideram-na como um enquadramento potencial para a investigação no domínio da interacção entre o computador e os humanos. Para caracterizar esta teoria (ver ponto 2.1) podemos salientar os seus seguintes princípios básicos de acordo com Kaptelinin (1996, cit. in De Keyser \& Nyssen, 2001, pp. 25-26, tradução livre) :

- É contextual - analisa a actividade humana no seu meio natural e dinâmico ;

- É orientada por objectivos - sustenta que há uma tensão (motivação, desejo, intenção) no sujeito face a um objecto, a qual provoca a actividade ;

- A tomada de consciência é construída através da interacção com o objecto - no início é um processo social, mediado por diversos tipos de ferramentas, que podem ser materiais ou conceptuais, como por exemplo a linguagem ;

- Através de processos de mediação permite a emergência da interiorização - esta interiorização consiste numa representação distorcida do objecto construída na acção e pela acção, a que Oshanin chamou de imagem operativa.

63 Nesta abordagem da prevenção influenciada pela teoria da actividade, é importante salientar que, de acordo com De Keyser e Nyssen (2001), a condição necessária para que os artefactos usados na prevenção se transformarem em instrumentos verifica-se quando os artefactos apoiam no nível individual ou no nível colectivo a realização das actividades humanas em contexto, apoiam a aquisição de conhecimentos, modificam a representação dos actores e sem criarem novos tipos de risco reduzem as probabilidades de ocorrência de incidentes, acidentes ou erros.

No quadro desta perspectiva, sustentada pela teoria da actividade, passamos a analisar alguns dos métodos/instrumentos mais utilizados na prevenção.

\subsection{Sistemas de informação de segurança}

Os sistemas de informação de segurança podem ser considerados como a restituição da experiência. Envolvem a compilação e a classificação de erros, incidentes e acidentes. Esta colecção é vital para uma boa gestão dos conhecimentos no terreno. Os resultados são endereçados, quer para os actores no terreno, quer para os decisores.

O processo de elaboração do sistema de informação de segurança envolve uma série de etapas. Um conjunto de dados em bruto acerca dos erros, incidentes ou acidentes são coligidos e depois transformados, num primeiro nível de análise, numa descrição ou num modelo que permite às pessoas compreender melhor o fenómeno. Por exemplo, um incidente é descrito por uma árvore de causas evidenciando as inter-relações causais dos factores de risco. De seguida, através de métodos estatísticos, é possível realizar uma análise de segundo nível tendo em vista generalizar e predizer situações de risco. Estas situações críticas são habitualmente denominadas situações prototípicas de risco, nas quais um acidente ou incidente se torna virtualmente inevitável, devido a uma combinação específica de factores (De Keyser \& Nyssen, 2001).

Existem múltiplas diferenças entre os sistemas de informação de segurança. Nem todos têm uma visão holística dos riscos e muitos tratam isoladamente cada um dos factores de risco. 0 que é comum a todos os sistemas de informação de segurança é a garantia de confidencialidade da fonte, funcionando muitos deles de forma voluntária com a finalidade de garantir que qualquer pessoa se sinta livre e segura ao relatar um problema (De Keyser \& Nyssen, 2001). 
s esquemas de classificação ou esquemas modelo utilizados recorrem a abordagens teóricas ou empíricas e, por vezes, a combinações das duas. Os modelos de Rasmussen e de Reason são particularmente utilizados nos sistemas de informação de segurança que utilizam classificações cognitivas, mas utilizam-se muitas outras classificações baseadas no conhecimento específico de um domínio ou de um contexto. $\mathrm{Na}$ escolha destas abordagens para classificar um erro, um incidente ou um acidente, ou para estabelecer a relação entre os factores que lhe estão associados, é importante que permitam salientar as possibilidades da fiabilidade humana na sua detecção e/ou recuperação e que ilustrem as eventuais circunstâncias/características do contexto técnico e organizacional que possam ter influenciado a sua origem ou o seu processo (idem).

A forma como é utilizada e explorada a informação constitui um dos aspectos mais relevantes na gestão dos relatórios de segurança. Se quisermos ser congruentes com a visão de que estes servem para modificar os conhecimentos e a compreensão das pessoas sobre os processos acidentais, incidentais ou de erro, sugerem-se as três seguintes possibilidades de exploração :

- $\circ$ Caso a caso. Constituem exemplos desta alternativa a publicação dos incidentes no jornal interno da empresa, mantendo o anonimato ; ou a sua análise e discussão durante acções de formação ou em reuniões de segurança ;

- Quantificação e tratamento estatístico dos resultados. Alternativa muito utilizada nos sectores de alto risco que monitorizam rigorosamente a evolução dos erros ou dos incidentes ;

- Determinação da probabilidade de ocorrência de um incidente ou acidente. Esta predição corresponde à tendência da Human Reliability Assessment de Hollnagel, embora actualmente se procure fazer tentativas para definir configurações de situações que envolvem uma elevada probabilidade de ocorrência de erros que possam ter consequências desastrosas, ou seja, as já referidas situações prototípicas de acidentes (De Keyser \& Nyssen, 2001, p. 29, tradução livre).

Na gestão eficaz dos modelos, dos métodos de classificação e das formas de exploração utilizados nos sistemas de informação de segurança o que parece essencial garantir é a sua adequação e adaptação às pessoas e ao contexto a que se dirigem. Nomeadamente, é importante que as abordagens utilizadas tenham em conta as reacções e a aceitação dos actores no terreno, particularmente na fase de introdução do sistema e nas suas formas de funcionamento e de exploração.

71 Em síntese, podemos salientar que um processo dinâmico de evolução "passo-a-passo", garantindo a confidencialidade, que rejeite a ideia de sanções e saliente os aspectos positivos do contexto e dos humanos na prevenção dos riscos, podem constituir importante contributo para a consolidação de um clima de confiança, essencial na boa gestão dos sistemas de informação de segurança, e na consequente construção de uma nova cultura de segurança.

\subsection{Simuladores como dispositivos de formação}

72 O reforço da fiabilidade humana através da formação constitui um dos procedimentos mais importantes nas políticas de prevenção. Neste ponto pretendemos ilustrar alguns desenvolvimentos preconizados pela autora na utilização de simuladores na formação, salientando a forma como a análise da actividade, a sua regulação e o contexto devem ser enfatizados (De Keyser \& Nyssen, 2001).

Laboreal, Volume $3 \mathrm{~N}^{\circ} 1$ | 2007 
73 Nesta ilustração começamos por nos distanciar da tendência muito difundida que consiste em utilizar os simuladores na formação de forma normativa visando orientar os formandos para a aquisição de determinados procedimentos ou para o diagnóstico correcto e rápido de problemas. Pretende, igualmente, contrariar a suposição de que os simuladores são modelos ou padrões da realidade. A intenção fundamental consiste em demonstrar a utilização dos simuladores na formação como instrumentos ao serviço das representações e das práticas dos formandos e formadores e de que forma os psicólogos podem mediar o processo de desenvolvimento de conhecimentos entre formadores e formandos, actuando, eles próprios, como instrumentos (De Keyser \& Nyssen, 2001).

Os simuladores são sobretudo utilizados na formação em domínios de alto risco nos quais os operadores não podem ser treinados nas situações reais devido a condições deontológicas, económicas e de segurança ou em situações de preparação de operadores que têm de apresentar desempenhos adequados na sua primeira exposição a situações críticas. Mas as potencialidades dos simuladores não se esgotam no plano didáctico, dado permitem o estudo do desempenho humano num contexto bastante realista, facto que possibilita um importante contributo para uma melhor compreensão da ocorrência de erros e de incidentes em vários cenários.

Contudo, existem problemas na relação entre a qualidade do desempenho em simuladores e em contexto real. As dificuldades decorrem do facto dos parâmetros de desempenho em contexto real nem sempre serem acessíveis nem fáceis de identificar. Estes devem ser inferidos de análises em profundidade do desempenho humano em situações reais. Para além de que, mesmos as situações simuladas que são percebidas como geradoras de stresse por parte do operador, não incluem todos os constrangimentos organizacionais que se verifica no sistema real. Assim, a avaliação do desempenho em simulador deve sempre ser confrontada com os dados obtidos pelos estudos do terreno (De Keyser \& Nyssen, 2001). No quadro destas dificuldades, existem estudos (De Keyser \& Nyssen, 1999 e Nyssen \& Javaux, 1996, cit. in De Keyser \& Nyssen, 2001, p. 34) que comparam o desempenho de operadores em simuladores, baseados em ecrãs e à escala natural [], com os dados obtidos através de estudos no terreno com a finalidade de verificar em que extensão as características dos simuladores influenciam o desempenho dos operadores. Conclui-se que os simuladores podem não ensinar a lidar com a complexidade e a variabilidade das situações reais porque usam situaçõesproblema previsíveis e estruturados de forma desarticulada da actividade no terreno (De Keyser \& Nyssen, 2001).

Os psicólogos podem apoiar os formadores/instrutores técnicos a reduzir o fosso entre situações reais e simuladas recorrendo ao estudo da actividade no terreno, evidenciando os seus constrangimentos em meio natural. Esta questão faz emergir a fidelidade dos simuladores que se refere ao grau de precisão com que os estes reproduzem o sistema e o seu contexto. A posição tradicional tem consistido em admitir que, melhorando a fidelidade física e funcional dos simuladores, incrementa o valor dos programas de formação. No entanto, vários estudos (Jentsch \& Bowers, 1998, cit. Iin De Keyser \& Nyssen, 2001, p. 35) têm mostrado que dispositivos computacionais de baixa fidelidade podem ser úteis na formação.

Os designers de computadores, tirando partido dos desenvolvimentos tecnológicos dos simuladores, têm continuado a tentar conseguir chegar a uma completa representação dos sistemas reais. Contudo, a principal função de um simulador não consiste em 
duplicar a realidade, mas em promover melhorias na aprendizagem (De Keyser \& Nyssen, 2001). O design de simuladores deveria, portanto, ser congruente com os objectivos da formação. Nalguns domínios, a ênfase tem sido feita prioritariamente na aquisição por parte dos formandos de conhecimentos, de procedimentos e de competências de solução de problemas tendo em vista o controlo de incidentes raros e potencialmente graves. Contudo, os investigadores que estudam as decisões em contexto real têm mostrado que nos sistemas modernos os dinamismos e a incerteza parecem ser a principal dificuldade dos decisores. As finalidades da formação com recurso a simuladores deveriam ser determinadas pela análise do desempenho humano em meio natural e não pelo recurso a critérios predefinidos (idem).

É neste contexto da nova abordagem do design dos simuladores que aparece o conceito de fidelidade psicológica que pode definir-se como "a extensão em que as situações simuladas geram condições psicológicas de acção similares às situações naturais, promovendo melhorias na aprendizagem das competências envolvidas nessas situações reais" (De Keyser \& Nyssen, 2001, p. 35, tradução livre). A fidelidade psicológica inscreve-se mais na similaridade das condições da acção do que na similaridade das características técnicas ou funcionais per se. Porque as condições da acção não podem ser derivadas exclusivamente dos modelos da função formal, devem ser determinadas através da análise da actividade. Adicionalmente, a análise da actividade ajuda a definir as funções da formação e da aprendizagem a serem garantidas pelos simuladores. Há um ciclo de mediação completo que continuamente produz conhecimentos que circula dos formadores/instrutores técnicos para os formandos e para os psicólogos - ver figura 3. 


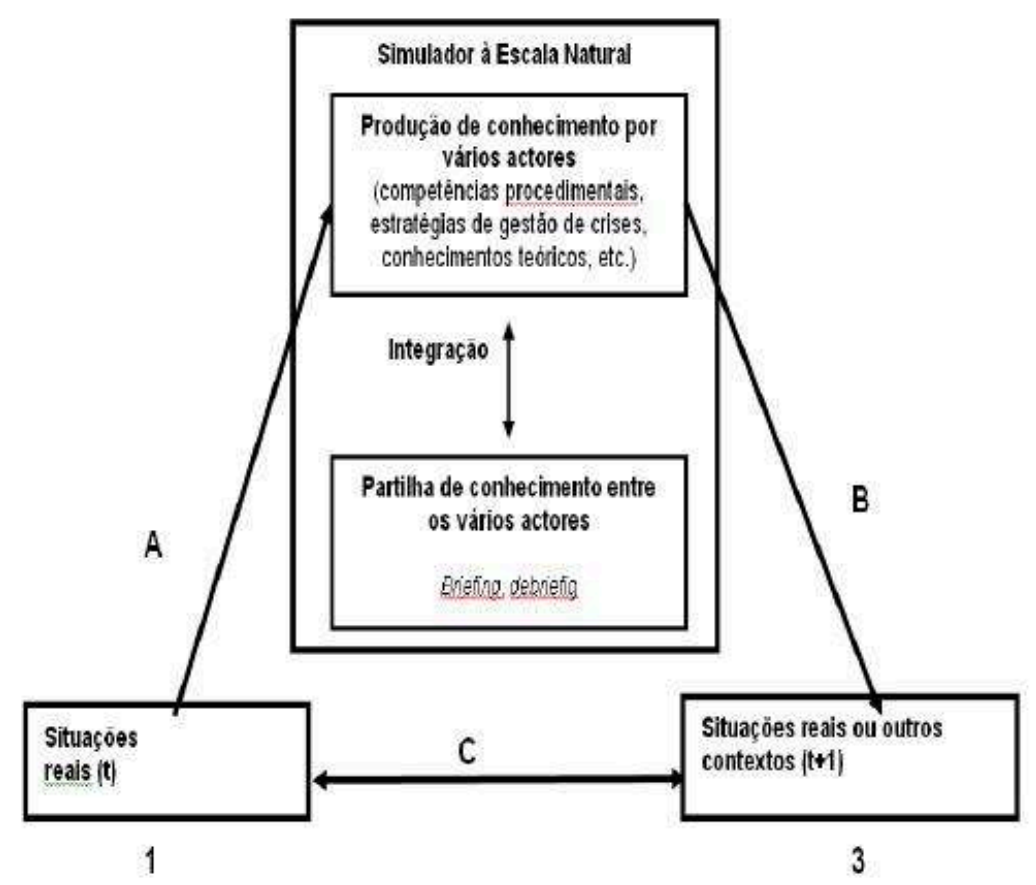

(Fonte : De Keyser \& Nyssen, 2000, cit. in De Keyser \& Nyssen, 2001, p. 36, tradução livre). Legenda : A - Identificação, Formalização e Estruturação do Conhecimento. B - Transferência da Aprendizagem. C Estudos de Avaliação.

79 Para uma melhor compreensão dos processos de mediação ilustrados nesta figura, as autoras consideram que :

O ciclo de mediação inicia-se com o passo 1, ou seja, uma análise da actividade em situação real. Esta análise habitualmente evidencia os constrangimentos e as dificuldades inerentes a estas situações - por exemplo o papel dos constrangimentos temporais na ocorrência de erro humano. Este conhecimento é mediado pelos psicólogos com os formadores. Esta mediação permite que os formadores enfatizem, no simulador, o que pode ser diferente da realidade e as questões da fidelidade psicológica do simulador. 0 passo 2 , a sessão de simulação, e sobretudo na sessão de discussão e análise (debriefing), o psicólogo ajuda os formadores a analisarem, de um ponto de vista psicológico, de que forma os formandos reagiram, resolveram o problema e cometeram erros. Esta sessão de discussão e análise (debriefing) - por vezes apoiada por registos vídeo - constitui um momento privilegiado para partilhar conhecimento entre os actores. 0 passo 3 é a transferência da aprendizagem para a situação. 0 psicólogo avalia esta transferência e evidencia as debilidades ainda existentes no conhecimento dos formandos - fazendo com que esta informação retorne à primeira etapa do ciclo (De Keyser \& Nyssen, 2001, p. 36, tradução livre).

81 A teoria da actividade diz-nos que a actividade é orientada por objectivos e que se regula a si própria no decurso da acção. No entanto, nas sessões de treino em simulador, frequentemente, os formadores/instrutores técnicos focalizam-se mais no desempenho técnico dos formandos do que no processo de regulação das actividades. Querem saber se o desempenho foi bem ou mal executado, querem que os formandos 
desempenhem adequadamente, mas por norma não exploram todas as informações que, durante o decurso da sessão, revelam um processo de regulação da actividade, como por exemplo :

- "Que tipo de erros os formandos produzem com maior frequência?

- Detectam-nos/recuperam-nos espontaneamente?

- A cooperação entre os formandos é eficiente ou não?

- De que forma os formandos interpretam e compreendem o cenário ?" (De Keyser \& Nyssen, 2001, p. 37, tradução livre).

A reflexão em torno destas questões pode ajudar significativamente os formandos a controlarem melhor a sua actividade real no futuro.

\subsection{Ajudas ao operador}

Muitas ajudas destinadas a auxiliar os operadores a realizarem as suas actividades em situações naturais não são utilizadas, são mal utilizadas ou induzem novos tipos de riscos. Outras, contudo, expandem tremendamente as capacidades humanas. Se compararmos o passado e o presente na história das ajudas, confrontam-nos com um facto novo. No passado, as ajudas eram desenhadas para apoiar o trabalho, reduzindo os constrangimentos físicos e cognitivos. Hoje, em muitos casos, o trabalho é projectado para ser apoiado pelas ajudas. A complexidade crescente dos sistemas técnicos já não é governável pelo operador sem ajudas técnicas (De Keyser \& Nyssen, 2001, p. 39). Esta afirmação é partilhada por muitos observadores da evolução dos sistemas técnicos e foi particularmente esclarecida por Amalberti (1996, p. 194) que circunscreveu uma área que definiu como uma área artificial do desempenho, unicamente acessível ao operador com recurso a ajudas.

Neste enquadramento coloca-se a questão de saber qual é exactamente o estatuto das ajudas por comparação com o estatuto do ser humano. De Keyser e Nyssen (2001) sustentam que :

- Para a teoria da actividade, instrumentos e humanos são apenas um, desde que o instrumento se torne um acessório funcional e o humano o mantenha sob controlo.

- Em contraste, a teoria da cognição distribuída introduz uma simetria entre homem e artefactos. Agentes naturais e artificiais cooperam num sistema cognitivo conjunto. A teoria da cognição distribuída refuta a noção de ajuda. De facto, visto literalmente, o termo 'ajuda' fixa a distribuição de papéis entre homens e artefactos. 0 sistema que formam está permanentemente a organizar-se e a adaptar-se a si próprio (p.39, tradução livre).

Para ilustrar a forma como as ajudas são vistas pela teoria da cognição distribuída e tomando como exemplo as ajudas à memória utilizadas no cockpit dos aviões, Hutchins (1995, cit. in De Keyser \& Nyssen, 2001, p. 39) considera que chamar a um artefacto específico ajuda à memória dos pilotos, é confundir as propriedades cognitivas do sistema funcional : o artefacto não ajuda os pilotos a lembrarem-se da velocidade ; ele é antes uma parte do processo pelo qual o sistema cockpit lembra a sua velocidade. Nesta concepção, nada é uma ajuda a priori, mas cada artefacto pode tornar-se uma ajuda num determinado momento, de acordo com o contexto e as exigências da acção. Mas a teoria da cognição distribuída não responde à questão fundamental formulada por Moray (1986, cit. In De Keyser \& Nyssen, 2001, p. 40) : se o operador não compreender completamente e dominar a situação, quem mais está responsável por este controlo? 
Na resposta a esta pergunta Moray é bastante claro ao defender que qualquer que seja o componente do sistema (seja ele um agente natural ou artificial) que detenha a autoridade última pela sua acção, deve ter um conhecimento completo das propriedades do sistema e deve ter o controlo completo (idem).

Apesar das ajudas se destinarem a apoiar a actividade humana, muitas vezes falham nas situações críticas, quando eventos inesperados modificam o meio de trabalho habitual. Este paradoxo foi descrito por Bainbridge (1987, cit. in De Keyser \& Nyssen, 2001, p. 40) como "ironia da automação" e Woods (Cook \& Woods, 1994 ; Cook, Woods \& Howie, 1992 ; Sarter \& Woods, 1992 ; Woods, 1986, cit. in De Keyser \& Nyssen, 2001, p. 40) relatou uma série de casos de "automação desajustada" em que as ajudas incrementam os constrangimentos cognitivos do operador no preciso momento em que deveriam socorrer esses constrangimentos.

Investigações sobre acidentes recentes têm revelado que a actual geração de dispositivos automatizados podem ter criado novos tipos de falhas no sistema homemmáquina resultantes de mudanças ocorridas na natureza do papel dos operadores no processo (De Keyser \& Nyssen, 2001). Estes passaram a ser supervisores e controladores que monitorizam o sistema, no qual intervém apenas quando é necessário efectuar mudanças ou quando ocorrem situações não previstas. $O$ operador foi retirado do círculo de controlo, provocando um decréscimo na fiabilidade do sistema. De facto, nestas condições de automatização crescente os operadores podem ter grandes dificuldades em desempenhar adequadamente o seu papel de supervisores e controladores, como se ilustra com a enumeração de alguns exemplos :

- Quanto mais autónoma a tecnologia, mais difícil se torna aos operadores desenvolverem representações explícitas sobre o seu funcionamento ;

- Algumas informações sensoriais relevantes (auditivas e tácteis) foram retiradas do meio de trabalho dos operadores;

- A velocidade dos processos pode fazer aumentar muito a complexidade. Algumas máquinas funcionam mais rapidamente que os operadores que passam a ter grandes dificuldades em controlá-las, facto que se agrava se o modo de funcionamento do operador e da máquina também forem muito diferentes (De Keyser \& Nyssen, 2001).

É comum a constatação de que novos dispositivos geram novas exigências nos indivíduos e grupos que têm de os operar e gerir. A presença destas exigências pode gerar novos riscos de erros e de incidentes que podem ser classificados como induzidos pelo design. Podemos, portanto, concluir que nos sistemas em que a "automação é desajustada" as ajudas não se configuram como instrumentos, no sentido atribuído por Vygotski a este conceito (De Keyser \& Nyssen, 2001).

\subsection{Design adaptado ao utilizador}

O conceito de design adaptado ao utilizador tem a ver com a tentativa de reavaliar as interacções homem-máquina no seu nível fundamental. Os princípios fundamentais dessa nova abordagem ao design passam pelo envolvimento dos utilizadoresalvo no processo de design, a facilitação da acção e a gestão do erro (De Keyser \& Nyssen, 2001).

A ideia de envolver os utilizadores ou os especialistas do domínio no processo de design não é original, mas a sua aplicação na prática tem-se frequentemente limitado a 
algumas etapas particulares do processo de design. Basta referir o ciclo da concepção para ficarmos elucidados :

- No início do ciclo, os potenciais utilizadores raramente conversam com os designers. São os "profissionais do factor humano", habitualmente psicólogos e ergonomistas, que fornecem aos designers a estrutura de referência respeitante à tarefa, ao meio de trabalho e às necessidades dos utilizadores;

- No desenvolvimento do protótipo, é mais fácil que os utilizadores sejam envolvidos no processo de design, especialmente para validar o protótipo. Esta integração pode tomar várias formas : questionários, observação das interacções dos humanos com o computador tanto em situações experimentais como nas situações de trabalho ;

- No final do processo de design, a funcionalidade do produto e, por vezes, o seu impacto na situação de trabalho é avaliado em situação de uso real, durante um período de tempo. Esta fase é particularmente importante para identificar de que forma os operadores ajustam o artefacto para o usarem como instrumento. A abordagem consiste em manter um registo das interacções entre os humanos e as ajudas, comparando e analisando continuamente o projecto planeado com o projecto real. Se forem identificadas disparidades devem ser empreendidas mudanças, quer no produto quer na situação de trabalho, para prevenir a ocorrência de erros ou incidentes induzidos pelo design. Contudo, nesta última etapa, mudar o produto torna-se muitas vezes impraticável, recorrendo-se a acções de formação e a procedimentos a observar como as medidas mais frequentes de protecção para promover a segurança (De Keyser \& Nyssen, 2001, p. 46, tradução livre).

91 Do ponto de vista da teoria da actividade, os sistemas de ajuda devem ser desenhados para apoiarem os operadores a realizarem tarefas de forma segura e eficiente nas condições de trabalho reais. Assim, a base para o seu design não deve ser a tecnologia em si mesma, mas antes as necessidades dos operadores em contexto, sob constrangimentos de tempo e demais recursos.

Porque é impossível prevenir todos os possíveis erros humanos, o design adaptado aos humanos deve suportar a gestão do erro, ou seja, deve incrementar tanto a resistência do sistema ao erro como a tolerância do sistema ao erro, contrariando a tradicional tendência dos projectistas de software e da engenharia industrial cuja intervenção tem sido orientada por objectivos ligados à limitação da ocorrência de erros. Em contraste com esta tendência, uma estratégia de gestão do erro tem uma dupla intenção : reduzir o número de erros e limitar as consequências adversas dos erros que ainda possam ocorrer. Esta estratégia comporta duas ideias :

- Sistemas resistentes ao erro, nos quais é muito difícil aos operadores humanos cometerem erros. Para promover a resistência o design inclui, por exemplo, funções impostas que limitam uma sequência de aç̧ões do utilizador ao longo de determinados passos, listas de verificação electrónicas que apoiam a realização de determinadas tarefas. Contudo, a utilização de novos dispositivos originam a possibilidade de erros imprevistos. Ferramentas que ajudem a detectar erros, como por exemplo os alarmes, são fundamentais na prevenção da propagação de um erro no interior do sistema, evitando, desta forma, as suas consequências negativas. Por esta razão, alguns investigadores consideram que a deteç̧ão e a forma como se lida com os erros é tão importante como a sua prevenção ;

- Tolerância dos sistemas que consiste na capacidade do sistema evitar as consequências negativas do erro. Numa situação de trabalho, todos os dias são cometidos grande número de erros, mas apenas muito poucos têm consequências negativas porque os erros são detectados pelas várias defesas que protegem o sistema evitando a sua propagação. As 
medidas de tolerância no design incluem : ferramentas que promovem a detecção do erro, que incrementam a compreensão do sistema por parte do operador, que limitam o sistema de um modo aceitável, que monitorizam a actividade das pessoas, que interpõe barreiras de segurança, etc. (De Keyser \& Nyssen, 2001, pp. 47-48, tradução livre).

\section{Reflexão final}

Se retomarmos a ideia esboçada na introdução sobre a necessidade de promover mudanças nas concepções e nas práticas da prevenção em Portugal, gostaríamos de salientar algumas ideias propostas por Véronique De Keyser que revelam potencial para estimular a reflexão e inspirar de forma sustentada a emergência de possibilidades de transformação das formas de perspectivar e de realizar as intervenções neste domínio.

Assim, propomos que a discussão sobre os contributos desta autora se estruture em torno das seguintes sugestões para a investigação e intervenção na área da segurança e saúde ocupacionais :

1. Abordagens alicerçadas em paradigmas de tipo contextual.

2. Papel central da análise da actividade de trabalho no estudo/ avaliação dos riscos e nas práticas da prevenção.

3. O ser humano considerado em contexto como agente de fiabilidade e regulador do sistema.

4. Métodos de intervenção e acção dos investigadores/interventores como instrumentos ao serviço da prevenção.

Antes de analisar em maior pormenor estes pontos, é importante assinalar que a União Europeia tem desempenhado um papel relevante na área da segurança e saúde no trabalho. Nomeadamente, o enquadramento legal que tem produzido, o financiamento de programas de investigação/intervenção e a criação de instituições vocacionadas para funcionarem como observatório e como meio de difusão de conhecimentos, constituem importantes instrumentos para a prevenção devido ao seu potencial para facilitar a criação de dinamismos globais e regionais ao serviço da promoção do bemestar e da garantia da segurança nos sistemas produtivos (De Keyser, 2001b). Neste enquadramento, salienta-se a Directiva 391/89/CEE como instrumento privilegiado para analisar riscos e formatar os processos preventivos porque está alicerçada numa abordagem que visa a adaptação do trabalho ao homem/mulher e sugere a necessidade de analisar os processos laborais na sua globalidade.

As duas primeiras sugestões apelam para a necessidade de repensarmos as tradicionais abordagens ancoradas em lógicas de cariz tecnicista e normativo que dominam as práticas da avaliação de riscos e da prevenção. Baseadas em procedimentos, normas e regulamentos (nacionais e internacionais) que a partir do exterior prescrevem/ sancionam os elementos e procedimentos a utilizar ou a evitar na concepção e no funcionamento de instrumentos ou de postos de trabalho, no pressuposto da existência de princípios de carácter geral que regulam o funcionamento dos indivíduos e dos processos produtivos.

Estas abordagens de carácter universalista dificilmente têm em conta a variabilidade do trabalho e das populações trabalhadoras. Frequentemente sustentam-se em reducionismos e simplificações, aparentemente cómodos, na ilusão de que os processos de trabalho se esgotam e coincidem com as funções e tarefas prescritas [10] e são 
empreendidos por entidades abstractas a que poderíamos denominar de "seres humanos médios".

Assim, sugerimos que o valor e o mérito das intervenções preventivas possa ser julgado privilegiadamente por critérios ligados à sua efectiva adequação e articulação com as condições concretas do contexto em que se realizam tendo em conta a sua transformação e adaptação aos trabalhadores, e não tanto pelo recurso a critérios genéricos e abstractos, inferidos da suposta validade universal e possibilidade de generalização, que dificilmente são adaptados/veis às especificidades de um terreno particular.

Neste enquadramento, a abordagem proposta por Véronique De Keyser salienta que a teoria da actividade pode ser considerada um terreno comum dos psicólogos do trabalho e a análise da actividade deve ser vista como elemento estruturador das intervenções, acentuando de forma muito evidente o contexto, a regulação e a mediação da actividade como factores determinantes da prevenção (De Keyser \& Nyssen, 2001).

Apesar da complexidade em operacionalizar o contexto na teoria da actividade, como vimos no ponto 2, as ferramentas da prevenção não podem deixar de tê-lo em consideração. Têm de perspectivar a actividade no seu meio natural, numa perspectiva sistémica. Para prevenir adequadamente os incidentes, acidentes e os erros, temos de conhecer os constrangimentos e os recursos da actividade em situações reais, pelo que é primordial que as fontes de informação sejam os relatórios de incidentes e os estudos do terreno e dos utilizadores (De Keyser \& Nyssen, 2001).

A terceira sugestão invoca a questão da importância atribuída aos humanos no funcionamento e pilotagem dos sistemas. Para iniciar a reflexão sobre esta importante dimensão da prevenção, podemos relembrar que em contraste com a teoria da cognição distribuída, que apaga as diferenças entre agentes naturais e artificiais em sistemas cognitivos conjuntos, a teoria da actividade salienta a especificidade dos seres humanos. Os humanos são simultaneamente fonte de elevada fiabilidade e de elevada infiabilidade. Nos meios naturais complexos a sua presença é uma garantia de segurança, dado que muitas vezes conseguem evitar ou minimizar as consequências dos incidentes. Esta posição prévia da teoria da actividade é inteiramente corroborada pela evidência dos estudos do terreno e dos relatórios de incidentes e acidentes, desde que a análise seja feita para além das circunstâncias imediatas do incidente e se tenha em conta o processo na sua globalidade. Não é de admirar, portanto, que os investigadores enraizados nesta tradição teórica promovam a concepção e utilização de ferramentas que apoiam a realização da actividade e salientam o operador como uma defesa natural contra incidentes, como protagonista da prevenção (idem).

Para esclarecer com rigor o papel dos humanos na regulação e fiabilidade dos sistemas, Véronique De Keyser analisa a evolução da regulação da actividade referindo que tem sido interpretada de dois pontos de vista :

- No início dos anos 60, Faverge $(1967,1970)$, e com ele toda a escola francesa da psicologia do trabalho, evidenciou como o operador constituía uma fonte de recursos, actuando como um regulador natural do sistema técnico, antecipando e detectando possíveis incidentes. Esta regulação era orientada para o sistema.

- No presente, a regulação da actividade é sobretudo orientada para o sujeito. São desenhados instrumentos para induzir uma orientação reflexiva nos sujeitos, levando-os a reflectirem sobre a sua própria actividade, a corrigirem os seus próprios erros, construírem meta- 
conhecimentos acerca do que sabem e do que podem fazer em segurança. (...) Esta nova filosofia consiste em admitir que as pessoas podem espontaneamente corrigir os seus próprios erros, se forem bem apoiadas pelas ajudas, formação e demais ferramentas utilizadas na prevenção (De Keyser \& Nyssen, 2001, p. 49, tradução livre).

Para concluir, a quarta sugestão desta reflexão final prende-se com o uso dos métodos e do protagonismo dos actores da investigação e da intervenção como instrumentos da prevenção. A abordagem proposta considera que os instrumentos produzem processos de mediação quando interligam sujeito e objecto. Os instrumentos mudam a representação interna que as pessoas têm do mundo e, consequentemente, transformam as suas práticas. São geradores de conhecimento. Podemos dizer a este propósito, que certos métodos desenhados com a intenção de assistir os operadores, não são por estes bem compreendidos nem apropriados. Não contribuem para uma verdadeira mediação. São artefactos, frequentemente localizados na área a que Amalberti (1996) descreveu como área de desempenho artificial. Contudo, a mediação não pode ser restringida às ferramentas técnicas. Vimos vários exemplos em que os mediadores são seres humanos. Quando, por exemplo, os psicólogos do trabalho ou os ergonomistas medeiam dados da actividade real obtidos através da análise dos processos de trabalho no terreno para os instrutores técnicos dos simuladores, agem como instrumentos num processo de geração de conhecimentos (De Keyser \& Nyssen, 2001).

\section{BIBLIOGRAFIA}

Amalberti, R. (1996). La conduite de systèmes à risque. Paris : Presses Universitaires de France.

De Keyser, V. (2001a). Evolution of ideas and actors of change. In V. De Keyser, \& A. Leonova (Eds.), Error prevention and well-being at work in Western Europe and Russia. Psychological traditions and new trends (pp. 3-23). Dordrecht : Kluwer Academic Publishers.

De Keyser, V. (2001b). Practices. In V. De Keyser, \& A. Leonova (Eds.), Error prevention and wellbeing at work in Western Europe and Russia. Psychological traditions and new trends (pp. 87-102). Dordrecht : Kluwer Academic Publishers.

De Keyser, V., \& Hansez, I. (1996). Vers une perspective transactionnelle du stress au travail : pistes d'évaluation méthodologiques. Les Cahiers de Médecine du travail, 33(3), 133-134.

De Keyser, V., \& Nyssen, A.-S. (2001). Activity and instruments. In V. De Keyser, \& A. Leonova (Eds.), Error prevention and well-being at work in Western Europe and Russia. Psychological traditions and new trends (pp. 25-49). Dordrecht : Kluwer Academic Publishers.

De Keyser, V., Nyssen, A.-S., Hansez, I., \& Javaux, D. (2001). Research and context. In V. De Keyser, \& A. Leonova (Eds.), Error prevention and well-being at work in Western Europe and Russia. Psychological traditions and new trends (pp. 51-85). Dordrecht : Kluwer Academic Publishers. 
De Keyser, V., \& Leonova, A. (Eds.) (2001). Error prevention and wellbeing at work in Western Europe and Russia. Psychological traditions and new trends. Dordrecht : Kluwer Academic Publishers.

Faverge, J.M. (1967). Psychosociologie des accidents de travail. Paris : Presses Universitaires de France.

Faverge, J.M. (1970). L'homme, agent de fiabilité et d'infiabilité du processus industriel. Ergonomics, 13(3), 301-327.

Leplat, J. (1985). Erreur humaine, fiabilité humaine dans le travail. Paris : Armand Colin.

Rabardel, P. (1995). Les hommes et les technologies. Approche cognitive des instruments contemporains. Paris : Armand Colin.

\section{NOTAS}

1. Na elaboração deste trabalho que pretende sintetizar algumas das ideias estruturantes da abordagem que Véronique De Keyser preconiza para analisar riscos e gerir a prevenção no domínio da segurança e saúde ocupacionais, baseamo-nos essencialmente numa conferência proferida pela autora na Faculdade de Psicologia e de Ciências da Educação da Universidade do Porto em Janeiro de 2001 e na obra editada pela autora no mesmo ano (De Keyser \& Leonova, 2001).

2. Designa-se por stakeholder qualquer actor - individual ou colectivo - que tenha interesses investidos num determinado domínio, ou que possa, de alguma forma, ser por ele afectado.

3. Véronique De Keyser ilustra bem a importância em reflectir sobre as abordagens que perspectivam a prevenção e sustenta a necessidade de se evoluir para “(...) uma experiência psicológica mais alargada e aprofundada do que a que era exigida na tradicional abordagem da enge- nharia humana" (De Keyser \& Leonova, 2001, p.XVII, tradução livre).

4. Paradigma pode ser definido como o sistema básico de crenças ou a visão do mundo que guia o investigador/interventor não apenas nas escolhas do método mas em opções fundamentais em termos ontológi- cos e epistemológicos.

5. Para salientar esta importante característica, Véronique De Keyser assume que a marca identitária da abordagem que aqui caracterizamos é assumidamente contextual. Isto é, assenta numa abordagem da prevenção indissociável da análise da actividade de trabalho. "Socorre-se tanto de métodos qualitativos, quanto de métodos quantitativos, enfa- tizando o recurso a metodologias cruzadas. Nesta abordagem, o papel da actividade é central: dá significado aos resultados da investigação e orienta, guia, as práticas preventivas" (De Keyser \& Leonova, 2001, p.XVIII, tradução livre). Em conclusão, assume-se que a característica contextual desta abordagem, herança da teoria da actividade russa, "se pode ser considerada como um viés, deve, também, ser considerada como um paradigma científico" (idem).

6. Baseado nas ideias de Vygotski, Rabardel (1995) propõe uma abor- dagem que salienta a mediação e se destina à concepção e à análise de actividades através do recurso a ferramentas. Nesta abordagem as ferramentas são constituídas por artefactos e instrumentos que se podem distinguir da seguinte maneira: "o artefacto é o invólucro, a embalagem material ou simbólica da ferramenta. O instrumento refere-se à utilização, apropriação e adaptação da ferramenta por parte do operador" (De Keyser \& Nyssen, 2001, p.26, tradução livre).

7. A fiabilidade é de um ponto de vista técnico "a probabilidade de um componente do sistema não avariar durante um dado intervalo de tem- po" (De Keyser, 2001, p.7, tradução livre).

8. Surgiu nos anos 30 na União Soviética, desenvolvida por Luria, Vygotski, Leontiev e Oshanin. 
9. Há vários tipos de simuladores que se assemelham mais ou menos com o mundo real. Uns são baseados em ecrãs, outros são à escala natural. Algumas das suas características, aparentemente menores, podem alterar dramaticamente a actividade dos formandos face à forma como esta ocorre no contexto real.

10. É importante termos em conta que na psicologia do trabalho de tradição francófona se distingue claramente o trabalho prescrito, a tarefa concebida e predefinida pelos conceptores e enquadradores, e o trabalho real, a actividade efectivamente realizada pelos operadores, tendo em conta compromissos dinâmicos que estes estabelecem, articulando os objectivos/regras prescritos, a variabilidade e os imprevistos com que se confrontam, os seus próprios objectivos, as suas caracterís- ticas individuais e colectivas, assim como as condições concretas de realização do trabalho.

\section{RESUMOS}

Apresenta-se a abordagem conceptual e metodológica proposta por Véronique De Keyser para gerir a prevenção e analisar riscos profissionais. É uma perspectiva que sustenta que as concepções e as práticas da prevenção devem decorrer e estruturar-se sempre a partir do estudo dos riscos em contexto, com a participação dos diversos actores envolvidos. Estruturamos a apresentação desta abordagem [1] em três grandes momentos. Iniciamos com a análise da evolução dos paradigmas utilizados na compreensão das ideias sobre a avaliação e prevenção de riscos. De seguida operacionalizamos os conceitos e as teorias que permitem caracterizar uma abordagem de tipo contextual na investigação/intervenção preconizada pela autora para este domínio. Concluímos com a apresentação dos métodos mais difundidos no estudo e na avaliação dos riscos, salientando a sua utilização como instrumentos ao serviço da transformação das formas de conceber a prevenção e as práticas que lhes estão associadas.

Se presenta el planteamiento conceptual y metodológica propuesta por Véronique De Keyser para gestionar la prevención y analizar riesgos profesionales. Es una perspectiva que sustenta que las concepciones y las prácticas de la prevención deben transcurrir y estructurarse partiendo siempre del estudio de los riesgos en contexto, con la participación de los diversos actores involucrados. Estos son solicitados a desempeñar papeles activos en el análisis de las actividades de trabajo efectivamente realizado y en la consecuente construcción de alternativas con la finalidad de concebir y de concretar transformaciones sostenibles y duraderas teniendo en cuenta la fiabilidad de los sistemas productivos, la garantía de la seguridad y la promoción de la salud y del bienestar de las poblaciones trabajadoras. Estructuramos la presentación de este planteamiento [1] en tres grandes momentos. Iniciamos con el análisis de la evolución de los paradigmas utilizados en la comprensión de las ideas sobre la evaluación y prevención de riesgos. A continuación pasamos a la operatividad de los conceptos y las teorías que permiten caracterizar un planteamiento de tipo contextual en la investigación/intervención preconizada por la autora para este dominio. Concluimos con la presentación de los métodos más difundidos en el estudio y en la evaluación de los riesgos, destacando su uso como instrumentos al servicio de la transformación de las formas de concebir la prevención y las prácticas que les están asociadas. 
L'approche proposée par Véronique De Keyser pour une gestion de la prévention et une analyse des risques professionnels est au centre de cet article. Il s'agit d'une perspective selon laquelle les conceptions et les pratiques de prévention doivent toujours émerger et se structurer à partir de l'étude des risques dans le contexte où ils surviennent, et associer la participation des divers acteurs concernés. La présentation de cette approche est structurée en trois moments. Le premier ouvre l'article avec une analyse de l'évolution des paradigmes qui ont soutenu la compréhension des idées dans le domaine de l'évaluation et de la prévention des risques. On procède ensuite à une opérationnalisation des concepts et des théories qui caractérisent l'approche contextuelle prônée par l'auteure pour la recherche/intervention. On conclut enfin avec un exposé des méthodes les plus diffusées dans l'étude et l'évaluation des risques, en mettant en évidence leur utilisation comme instruments au service d'une transformation des façons de concevoir la prévention et les pratiques qui lui sont associées.

We present the conceptual and methodological approach proposed by Véronique De Keyser to managing prevention and analysing professional risks. In this perspective conceptions and practices of prevention should always emerge and be structured by the risk analysis accomplished in context and with the participation of the concerned actors. We have structured the presentation of this approach in three parts. We begin by analysing the evolution of paradigms that support the understanding of risk evaluation and prevention management. Next we operationalise the concepts and the theories that characterise the contextual approach envisaged by the author to research/intervention in this domain. We conclude with the exposition of the most widespread methods in risk evaluation study, emphasising their use as instruments in order to promote transformations in views on conceptions and practices of prevention.

\section{ÍNDICE}

Mots-clés: prévention, méthodes d'analyse de risques, contexte, analyse de l'activité, médiation instrumentale

Palavras-chave: prevenção, métodos de análise de riscos, contexto, análise da actividade, mediação instrumental

Keywords: prevention, risk analysis methods, context, work activity analysis, instrumental mediation

Palabras claves: prevención, métodos de análisis de riesgos, contexto, análisis de la actividad, mediación instrumental

\section{AUTOR}

\section{CAMILO VALVERDE}

Universidade Católica Portuguesa Faculdade de Economia e Gestão Rua Diogo Botelho, oㅡ 1327, 4169005 Porto Portugal cvalverde@porto.ucp.pt 